\title{
LAS FORMAS DEL PLURALISMO
}

\author{
Roberto García Jurado*
}

El concepto del pluralismo ha recorrido un trayecto histórico muy peculiar: en el pasado fue denostado y rechazado, pero en la actualidad tiene una connotación indiscutiblemente positiva; se le considera incluso un valor ético altamente estimable en nuestra civilización y uno de los componentes institucionales básicos de los gobiernos democráticos. Pero no siempre ha sido así. Hobbes, por ejemplo, planteaba que la mejor base social y política de un Estado era la homogeneidad de sus integrantes, por lo que toda liga o corporación que agrupara a un cierto número de súbditos para difundir determinadas doctrinas políticas u organizar su defensa común debía considerarse ilegal y perniciosa. Hobbes argumentaba que el Estado debía ser considerado una liga de todos los súbditos para el bien común, por lo que la segmentación de una parte de ellos en una sociedad particular sólo podía ser interpretada como una tentativa facciosa y tendiente a la conspiración.

Es probable que no pueda esperarse nada menos que una opinión como la anterior por parte de Hobbes, el teórico por excelencia del contractualismo absolutista, sin embargo, una opinión muy parecida la da también Rousseau, quien en más de un sentido podría considerarse el primer teórico de la democracia moderna. Para él, la mejor forma de conocer la voluntad general del pueblo era procurar que los ciudadanos estuvieran adecuadamente informados y que meditaran sobre los asuntos a decidir de manera aislada e individual, es decir,

\footnotetext{
* Departamento de Política y Cultura, UAM-X.
} 
ROBERTO GARCÍA JURADO

debía tratarse de que su deliberación no se contaminara con los juicios y opiniones de otros. Sólo un procedimiento de este tipo podía garantizar que el resultado fuera bueno; que la voluntad general fuera atinada y correcta. Rousseau argumentaba que la suma de las pequeñas diferencias de opinión individuales emitidas por toda la ciudadanía producía una voluntad general equilibrada y certera, por lo que el surgimiento de asociaciones parciales lo único que provocaría sería la distorsión de la voluntad general, ya que las opiniones emitidas por éstas tendrían un carácter general para los miembros de la asociación, pero sólo serían particulares dentro del Estado. De este modo, en cuanto mayor tamaño tuviera la asociación o asociaciones que existieran dentro de un Estado, mayor sería la distorsión producida en la voluntad general. En este sentido, la única manera de contrarrestar o neutralizar esa tendencia sería aumentar el número de asociaciones hasta que su multiplicidad redujera la desigualdad y desequilibrio introducidos.

No obstante, algún tiempo después, ya en el siglo XIX, Tocqueville describía la función insustituible que desempeñaban las asociaciones civiles y políticas en la democracia norteamericana, las cuales no entorpecían u obstaculizaban en modo alguno la operación del gobierno, sino todo lo contrario, constituían un punto de apoyo básico para ese régimen. Posteriormente, de un modo similar y llevando esta idea al extremo, Durkheim planteaba incluso que las sociedades modernas requerían imperiosamente de este tipo de asociaciones para lograr la plena organización e integración social, particularmente de las corporaciones profesionales, en las cuales hacía recaer el mayor peso de esta responsabilidad.

Como puede observarse, a pesar de que en el pasado este concepto designaba un rasgo negativo de la sociedad o el gobierno de un Estado, desde el siglo XIX, y sobre todo en el siglo XX, se invirtió esta valoración y se convirtió en una cualidad positiva y apreciada. Más aún, este concepto se llegó a fundir con el de democracia para originar el de democracia pluralista o pluralismo democrático, el cual designa un tipo de democracia en el que las asociaciones civiles y políticas desempeñan una función básica, tal y como Tocqueville lo había descrito 
para el caso de la democracia en América. No obstante la inversión del valor de este concepto y del largo trayecto histórico y teórico que ha recorrido, en la actualidad sigue siendo objeto de reflexión y polémica su significado; sigue siendo válido y necesario preguntarse qué significa el pluralismo en las sociedades contemporáneas y qué tipo de pluralismo es el que se requiere.

El concepto del pluralismo ha desempeñado dos cometidos relevantes en la teoría democrática contemporánea: uno descriptivo y otro prescriptivo. En la obra de los primeros pluralistas ingleses y norteamericanos, el pluralismo apuntaba a describir la forma en que realmente funcionaban las democracias, en este sentido, el pluralismo constituía principalmente una opción explicativa frente al modelo clásico propuesto por la teoría de la soberanía, la cual presentaba al gobierno de la sociedad como la expresión del poder soberano ejercido por los representantes de ella emanados. ${ }^{1}$

La teoría de la soberanía planteaba esencialmente que el ejercicio del poder del Estado radicaba en un solo centro, en el gobierno, al cual correspondía tomar todas o la mayor parte de las decisiones que afectaban a la sociedad. Sin embargo, para los pluralistas, esta explicación resultaba un tanto incongruente o, al menos, insuficiente. Denotaban que la realidad del poder político era distinta, pues en ella la acción gubernamental se veía frecuentemente desviada, atenuada o frenada por la acción de una serie de grupos, asociaciones y organizaciones sociales que se erguían frente al gobierno, frente al poder del Estado, para expresar y exigir la atención de sus intereses. ${ }^{2}$

En este sentido, la teoría del pluralismo de presentaba como un aporte relevante a la teoría política, ya que con ella se entendía y explicaba mejor el funcionamiento real de los sistemas políticos, particu-

${ }^{1}$ Véase Gabriel Almond, "Pluralismo, corporativismo y memoria profesional”, en Una disciplina segmentada. Escuelas y corrientes en las ciencias políticas, 1999, México, CNCPAP-FCE.

${ }^{2}$ Véanse los dos textos clásicos del pluralismo político: Arthur Bentley, The process of government, 1967, Chicago, Chicago University Press; y David Truman, The governmental process, 1951, New York, Alfred A. Knoph. 
ROBERTO GARCÍA JURADO

larmente de países como Estados Unidos, en donde tradicionalmente este tipo de grupos de interés se manifestaba de una forma vigorosa.

No obstante este contenido original, esencialmente descriptivo, el pluralismo adquirió posteriormente también uno prescriptivo. Si en un primer momento el pluralismo fue visto como una desviación del modelo clásico de gobierno democrático o como la adaptación peculiar de éste a un tipo de sociedad como la norteamericana, posteriormente se convirtió además en un modelo general sustituto, el cual debía adoptarse no sólo por necesidad o como solución intermedia, sino como un modelo de sistema político que aportaba múltiples ventajas y que constituía un valor por sí mismo. ${ }^{3}$

El modelo de la democracia pluralista se convirtió en un valor debido esencialmente a dos razones: al temor del ejercicio tiránico del poder estatal y a las imperfecciones de la representación política democrática. Para el liberalismo clásico del siglo XIX, el cometido más importante de la política no era precisamente alcanzar o construir un buen gobierno, sino evitar que éste excediera sus funciones estrictamente necesarias y se convirtiera en un factor determinante y decisivo para la convivencia social. ${ }^{4}$ Para evitarlo, trataba de buscar e institucionali-

zar mecanismos para contener el poder del Estado, a lo cual podían contribuir sustancialmente el conjunto de organizaciones y grupos de interés que el pluralismo resalta y que podían situarse frente al gobierno para moderar sus alcances y pretensiones.

En lo que respecta a la representación política democrática, el pluralismo se presentaba como un medio para complementarla y mejorarla, tratando de suplir así las carencias que las instituciones clásicas de representación política siempre han mostrado. De este modo, a pesar de que en las instituciones democráticas las tareas de la representación

${ }^{3}$ Véase Robert Dahl, Los dilemas del pluralismo democrático, 1991, México, Alianza-CONACULTA; y Robert Dahl, La poliarquía. Participación y oposición, 1989, Buenos Aires, REI.

${ }^{4}$ Un ejemplo típico y extremo de este tipo de liberalismo lo ofrece Herbert Spencer, El individuo contra el Estado, 1977, España, Júcar. 
tradicionalmente habían recaído sobre los partidos políticos y los parlamentos, la recurrencia a otros medios de expresión y manifestación política hacían evidente la necesidad y conveniencia de contar adicionalmente con organizaciones de otro tipo; con organizaciones que pudieran influir legítima y directamente en las agencias gubernamentales, en las instituciones parlamentarias y en los propios partidos, de manera que multiplicaran así los canales de expresión política y abrieran las posibilidades de satisfacer expectativas o intereses específicos de algunos sectores sociales.

Así, el pluralismo clásico presentado por los teóricos anglosajones se refería esencialmente al terreno político, a la pluralidad de grupos o asociaciones con intereses específicos que deseaban ver cumplirse en el plano del diseño y operación de las políticas públicas. Sin embargo, en la actualidad, cuando se habla de pluralismo no sólo se tiene presente la pluralidad en el ámbito político, sino que también se refiere a otros dos ámbitos, al puramente social y también al cultural. Por esta razón, cuando en la actualidad se alude al concepto del pluralismo es necesario tener presente su significación e implicaciones en estas tres áreas.

\section{El pluralismo político}

En el ámbito político, como se dijo antes, el pluralismo significa esencialmente la existencia de una multiplicidad de organizaciones y grupos que compiten abiertamente por obtener o influir en el poder político. Dentro de estos grupos destacan obviamente los partidos políticos, los cuales tradicional y doctrinariamente han sido las instituciones que desempeñan esa función; son los mecanismos que las democracias aceptan y reconocen como los medios legítimos para obtener el poder político. Sin embargo, en el pluralismo político contemporáneo los partidos no son los únicos protagonistas, además de ellos se reconoce y acepta la participación de al menos otros dos tipos de agrupaciones; las organizaciones sociales que participan en política y las diversas agencias gubernamentales encargadas de elaborar las políticas públicas. 
ROBERTO GARCÍA JURADO

Por lo que respecta a los partidos, el pluralismo significa precisamente la diversidad, multiplicidad y competencia de los partidos. En la actualidad resultaría obvio señalar que la política está protagonizada por una pluralidad de partidos, sin embargo, es necesario advertir que esta situación es relativamente reciente, pues aún en las que podrían considerarse las democracias más añejas, apenas hace un par de siglos que se presenta legítimamente esta competencia. En efecto, antiguamente la lucha abierta por la obtención del poder político había sido condenada y reprobada por doquier; se consideraba que una competición de este tipo no sólo tendía a desgarrar el Estado, sino que también el enfrentamiento de estas fuerzas políticas podía debilitar y cuestionar el ejercicio del poder soberano. Por estas razones, durante mucho tiempo se llamó facciones a los grupos que perseguían el poder político, facciones y no partidos, porque entonces se consideraba que la competencia política conducía a la desintegración pero nunca a la comunión. ${ }^{5}$

No obstante, la aceptación de la lucha abierta por la obtención del poder político no es sólo algo del pasado, en el presente sigue siendo una práctica ilegítima o poco real, incluso podría decirse que en cierto sentido durante el siglo XX la resonancia del pluralismo se debió precisamente a la crítica implícita que éste representa hacia las dictaduras y los regímenes totalitarios. En la actualidad persisten algunos sistemas de partido de Estado que no admiten en modo alguno la existencia de otros partidos y controlan el gobierno como si fuera un patrimonio exclusivo. En estos términos, el pluralismo es lo opuesto y la alternativa frente a los sistemas monistas, en donde un solo partido, una sola institución o un solo grupo controlan el gobierno. ${ }^{6}$

La pluralidad en este sentido significa que exista una variedad de partidos políticos, al menos dos, sin embargo, aunque podría parecer que una vez superada la frontera de dos partidos se entra en el terreno común de la pluralidad política, es necesario advertir que el grado de

${ }^{5}$ Véase Giovanni Sartori, Partidos y sistemas de partido, 1987, Madrid, Alianza.

${ }^{6}$ Véase T. J. Pempel (comp.), Democracias diferentes, 1991, México, FCE. 
multiplicidad partidaria afecta notablemente el conjunto y la densidad de la pluralidad política. En un sistema bipartidista como el de Estados Unidos, por ejemplo, la alternancia absoluta en el poder obliga a que las ofertas electorales de uno y otro partido sean lo más amplias e incluyentes posible. Los partidos de este tipo de sistemas no pueden pretender representar a un solo sector de la sociedad, si así lo hicieran, jamás podrían ganar una sola elección. Un partido de estos sistemas, por fuerza, debe tratar de presentarse como representante de todos los sectores sociales, al menos de la mayor parte de ellos, pues si no lo hace así el resultado más seguro es que pierda la contienda ante el otro partido.

En los sistemas bipartidistas los partidos no pueden identificarse con una sola ideología, un solo sector social o un grupo, deben abrirse inclusivamente, pero al hacerlo, su propuesta resulta tan general, distante y ecléctica que el elector medio se siente muy poco identificado con cualquiera de ellos. En estas condiciones, la distancia que se abre entre los partidos y la sociedad a la que dicen representar es acortada por una pluralidad de organizaciones y asociaciones que representan a sectores y grupos específicos, encargados de presentar y luchar por conseguir sus propios intereses. De este modo, la representación política que en este tipo de sistemas ofrecen los partidos se complementa y refuerza con este tipo de organizaciones, las cuales se presentan ante el gobierno y los propios partidos como interlocutores válidos y efectivos. ${ }^{7}$

Sin embargo, en los sistemas multipartidistas, particularmente en los más extremos, la multiplicidad de partidos modifica sensiblemente el carácter del pluralismo. En estos casos no hay una alternancia clara y absoluta en el gobierno, ya que éste es controlado por una coalición de partidos más o menos estable o por un partido dominante y alguno o algunos asociados. Así, los partidos no tienen necesidad de presumirse representantes de toda la sociedad o de una gran parte de sus sectores, basta con que atraigan y aglutinen las simpatías de un sector

${ }^{7}$ Véase Seymur Martin Lipset, La primera nación nueva, 1992, Buenos Aires, EUDEBA. 
ROBERTO GARCÍA JURADO

relevante para que su concurso en el gobierno sea garantizado. Aunque existen partidos que tratan de abarcar al conjunto del electorado, en este tipo de sistemas la permanencia y consistencia de los resultados electorales parece estar determinada por la disposición de una clientela electoral más o menos estable.

Los sistemas multipartidistas se caracterizan así por ofrecer una mayor variedad de alternativas y propuestas políticas, con lo cual se atenúa la necesidad de algunos sectores sociales para contar con una organización que les dé expresión política propia. Esto no significa necesariamente que los sistemas bipartidistas alienten la actividad asociativa y que los multipartidistas la hagan superflua, muchos otros factores intervienen para alentar o frenar el surgimiento de este tipo de organizaciones, sin embargo, resulta claro que el sistema de partidos es un factor importante para determinar el grado o la densidad del pluralismo político en una sociedad y de las funciones específicas que desempeñan las asociaciones y organizaciones sociales en él. ${ }^{8}$

Además de los partidos, como se dijo antes, el pluralismo político incluye a las organizaciones y asociaciones que participan en política, más aún, en muchas ocasiones el concepto de pluralismo evoca en primer término a este tipo de entidades. Las organizaciones y asociaciones que participan en política tienen como fin esencial tratar de influir en el poder político, específicamente buscan modificar, favorecer o frenar las políticas públicas que se vinculan con sus intereses. En términos más generales, funcionan como instituciones que median entre la sociedad y el Estado; ya sea que se les conciba en su carácter defensivo ante el poder del Estado o como mecanismos de enlace y comunicación.

Muy probablemente Estados Unidos sea la cuna de este tipo de asociaciones, y sean también el ejemplo más típico del pluralismo entendido de este modo. Ya Tocqueville se había referido ampliamente a la actividad asociativa de los estadounidenses. Señalaba que una sociedad democrática como ésta no sólo tendía a propiciar la asociación de sus ciudadanos para realizar las empresas comunes, sino que incluso

${ }^{8}$ Véase Philippe Schmitter, "La consolidación de la democracia y la representación de grupos sociales”, en Revista Mexicana de Sociología, n 3/93. 
su existencia era del todo punto necesaria, ya que en este tipo de sociedades no había ninguna otra defensa en contra de un partido, una facción o un gobernante que trataran de ejercer el poder tiránicamente, e incluso constituían un freno ante la tiranía de la mayoría. Tocqueville explicaba que los norteamericanos aprendían esto desde su nacimiento; aprendían que sólo podían confiar en sus propias fuerzas para desempeñar las tareas de la vida y que siempre había que ver con desconfianza y recelo a la autoridad social.

La animosidad asociativa política y civil que Tocqueville observaba evolucionó hasta convertirse en uno de los rasgos más típicos de este sistema político y dar origen al lobbismo, una de las prácticas parlamentarias más socorridas en ese país, cuyo modelo ha sido imitado y exportado a muchos otros sitios. No obstante, a pesar de la gran difusión de esta práctica, en algunos países, como en los propios Estados Unidos, se ha llegado a extremos lamentables e inadmisibles, y aunque el pluralismo produce inevitablemente ciertas formas de lobbismo, no cabe duda que debe evitarse llegar al grado de que la actividad parlamentaria se base en él. ${ }^{9}$

Por último, el pluralismo político debe incluir además de los partidos y organizaciones civiles a las distintas agencias e instituciones gubernamentales que participan en la confección de las políticas públicas. No es muy común incluir a las distintas entidades del gobierno en ese terreno, de hecho, la idea más aceptada es que el gobierno es un ente unido y homogéneo, que responde a un solo centro coordinador y decisorio de manera uniforme. Pero no siempre es así.

Las sociedades modernas son sociedades complejas; sus estructuras, funciones y normas se han venido diversificando y especializando al grado de que forman un complejo de prácticas e instituciones que las alejan notablemente de las sociedades simples y homogéneas. De una manera muy similar, los gobiernos modernos han venido creciendo y especializándose, difuminando la idea tradicional del gobierno controlado por un monarca o un príncipe que dictaba los lineamientos polí-

${ }^{9}$ Véase Robert Dahl, Democracy in the United States: promise and performance, 1972, Chicago, Rand McNally. 
ROBERTO GARCÍA JURADO

ticos generales a los cuales debían someterse de manera uniforme e incondicional todas las partes de éste.

Los gobiernos no funcionan ya de ese modo. En la concepción tradicional prevalece la idea de un gobierno jerarquizado, piramidal y homogéneo, lo cual no corresponde ya exactamente a su nueva conformación. En los gobiernos modernos la proliferación de agencias y entidades públicas de distintos tipos ha propiciado que estas relaciones típicas de verticalidad sean complementadas y modificadas por una gran cantidad de relaciones horizontales y diagonales, volviendo más compleja su operación. Esta transformación ha propiciado que muchas de las decisiones de gobierno y la propia elaboración de las políticas públicas no dependan ya autárquicamente de una sola agencia gubernamental, ha propiciado que en este tipo de procesos intervengan varias y que lo hagan con distintos niveles de responsabilidad. Esto implica que dentro del mismo gobierno deba darse un proceso de disputa, negociación y acuerdo para poner en marcha las políticas públicas. ${ }^{10}$

Esto no significa de ningún modo que hayan desaparecido las líneas de mando verticales y que el gobierno no deba seguir presentándose ante la opinión pública como un gobierno responsable que actúa de manera unitaria. Los gobiernos modernos deben seguir asumiendo esta responsabilidad, pero ello no implica que puedan pasarse por alto las dificultades que se enfrentan para lograrlo. Del mismo modo, tampoco debe equipararse la independencia y autonomía de los partidos políticos y las asociaciones civiles con las que tienen las agencias públicas, está claro que las de éstas es mucho menor y muy distinta. Es evidente que se trata de pluralidades distintas, pero a pesar de ello sería conveniente incluir siempre a las distintas agencias públicas cuando se piensa en el pluralismo político.

Estos tres tipos de entidades a las que se refiere el pluralismo político, los partidos, las organizaciones civiles y las agencias públicas, tienen el cometido fundamental de impedir que las decisiones políticas se produzcan en un solo centro de poder o, al menos, que su ejecución se vea

\footnotetext{
${ }^{10}$ Véase Raymond Aron, Ensayo sobre las libertades, 1990, Madrid, Alianza.
} 
condicionada a la anuencia, indiferencia o crítica de este tipo de entidades. Además, en conjunto, pretenden contribuir a reducir el déficit de representación política que siempre está presente en las democracias modernas. Sin embargo, la teoría del pluralismo es susceptible de importantes críticas que no pueden pasarse por alto.

En primer lugar, el pluralismo político ha sido incorporado a la teoría democrática tanto en su aspecto descriptivo como prescriptivo, sin reparar suficientemente en que existen algunos sistemas políticos a los que describe o se ajusta de un mejor modo que a otros. Es decir, el pluralismo político es un rasgo particularmente saliente de la democracia en países como Estados Unidos, en donde los grupos de interés tienen una función política fundamental. No bastante, esto no ocurre así necesariamente en otro tipo de sistemas, en donde aunque existe el pluralismo, su importancia es mucho menor. ${ }^{11}$

En segundo término, los planteamientos clásicos del pluralismo generalmente colocan al Estado en una posición neutral, situado más allá de cualquier influencia o condicionamiento político proveniente de la sociedad. Para el pluralismo, el Estado se ve reducido a una mera caja registradora que simplemente contabiliza las entradas y salidas en uno u otro sentido para hacer una suma o resta de todos ellos y dar un resultado aséptico y balanceado. El Estado se presenta así como una institución sin mayores atribuciones que las de árbitro de las fuerzas sociales en competencia, en la cual cada una de ellas obtiene del poder y los recursos públicos una parte alícuota y proporcional a su fuerza, satisfaciendo sin mayores conflictos sus aspiraciones y las del resto de los competidores. ${ }^{12}$

En tercer lugar, la mayor parte de los teóricos del pluralismo plantean que en este tipo de sistemas todos los grupos tienen la misma capacidad de organización y expresión política, lo cual les garantiza que sus

${ }^{11}$ Aunque su interpretación ha sido muy discutida, véase la aplicación de la teoría del pluralismo al caso británico en S. E. Finer, El imperio anónimo. Un estudio del lobby en Gran Bretaña, 1966, Madrid, Tecnos.

${ }^{12}$ Véase David Held, Modelos de democracia, 1992, México, Alianza; y Roger Benjamin, Los límites de la política, 1992, México, Alianza. 
ROBERTO GARCÍA JURADO

reclamos y expectativas sean atendidos en igual consideración que los del resto de los participantes. Con ello presuponen que todos los sectores sociales tienen más o menos la misma preparación y propensión a organizarse políticamente, por lo que basta su sola voluntad en este sentido para que obtengan la representación política que desean. Sin embargo, no toman en cuenta que ni todos los sectores sociales tienen la misma capacidad de organización, ni que no todas las organizaciones sociales tienen la misma influencia política, lo cual muestra que la competencia política implícita en el pluralismo no es todo lo neutral, imparcial y equitativa que se pretende. ${ }^{13}$

Finalmente, en cuarto sitio, el pluralismo concibe al gobierno como un ente pasivo y neutral dentro de la democracia, el cual no tiene otra función que sopesar los distintos reclamos sociales y tomar imparcialmente las decisiones que del balance se desprendan. Sin embargo, al menos desde Weber, ya se ha mostrado cómo la burocracia es un cuerpo y ente social con sus propios intereses, lo cuales pretende servir valiéndose de su posición dentro del Estado, por lo que no puede sencillamente asignársele una posición neutral. ${ }^{14}$

\section{El pluralismo social}

El pluralismo social tiene una gran cantidad de similitudes con el pluralismo político, pero también notables diferencias. Para comenzar, una de las diferenciaciones que hay que destacar es que pluralismo social no es lo mismo que sociedad plural. En términos semánticos no debía haber diferencia laguna, la simple inversión de términos no debía alterar el contenido, sin embargo, en la teoría política y sociológica, se ha dado un significado distinto a cada uno de ellos.

${ }^{13}$ Véase Martín Smith, “El pluralismo”, en David Marsh y Gerry Stocker (eds.), Teoría y métodos en la ciencia política, 1995, Madrid, Alianza; y Eduard Gonzalo y Ferran Requejo, “Las democracias”, en Miguel Caminal Badía (ed.), Manual de ciencia política, 1999, Madrid, Tecnos.

${ }^{14}$ Véase Gabriel Almod, op. cit. 
Una sociedad plural es aquella en la cual la población se divide en una serie de grupos sociales claramente diferenciados y separados, que tienen un elenco de características comunes que les permiten tener una identidad, existencia y expresión propia que los diferencia tanto de los otros grupos como del conjunto social. Esto significa, expresándolo de otro modo, que una sociedad plural es aquella que no está integrada por completo, que no puede identificarse por un tipo social homogéneo. En este tipo de sociedades existen distintas etnias, comunidades religiosas, razas y grupos lingüísticos que no se han disuelto en el conjunto social y, por el contrario, se manifiestan vigorosamente. En este sentido, el concepto de sociedad plural puede equipararse en muchos sentidos al de pluralismo cultural. ${ }^{15}$

El pluralismo social, en cambio, significa algo distinto. Esencialmente se refiere a la existencia de un amplio número de asociaciones y organizaciones sociales en las cuales se agrupan los individuos con el fin de alcanzar objetivos particulares o cultivar aficiones comunes. Estas organizaciones tienden a establecer una multiplicidad de relaciones sociales que vinculan a sus miembros tanto al interior como hacia el exterior contribuyendo de manera sustancial a la integración de todo el conjunto social. Así, el principal cometido del pluralismo social es impedir que los diferentes grupos sociales se aíslen y separen entre sí, esto es, evitar que las divisiones sociales básicas que se forman de manera natural por las relaciones económicas, la distribución geográfica o la pertenencia a religiones distintas se acentúen al grado de promover discordia o, incluso, la segmentación absoluta. Desde este punto de vista, lo que hace el pluralismo es acercar y vincular por medio de estas organizaciones a individuos que de otra manera permanecerían ajenos, es decir, propicia que los individuos entren en contacto por este medio aunque en otros aspectos sociales se diferencien y alejen notablemente. ${ }^{16}$

De acuerdo a los planteamientos teóricos de los principales pluralistas, para que se cumpla cabalmente con este objetivo las organiza-

${ }^{15}$ Véase Arend Lijphart, Democracia en sociedades plurales, 1988, México, Prisma.

${ }^{16}$ Véase Seymur Martín Lipset, El hombre político, 1993, México, REI. 
ROBERTO GARCÍA JURADO

ciones sociales deben cumplir dos requisitos ineludibles: deben ser auténticamente voluntarias y permitir la afiliación múltiple. Las organizaciones sociales deben ser absolutamente voluntarias porque eso evita que el pluralismo social sea artificial y tenga una existencia meramente formal. Este peligro se presenta principalmente en algunos tipos de regímenes autoritarios en los cuales los individuos están obligados a pertenecer a determinadas organizaciones. Un ejemplo típico de estos regímenes es el totalitarismo, en el cual el Estado trata de penetrar y controlar todas las actividades del individuo, para lo cual crea una serie de corporaciones y organizaciones de adherencia forzosa y de los más diversos tipos con el fin de abarcar todas las actividades vitales de los hombres y ejercer así un control total. Evidentemente, este tipo de organizaciones no permiten alcanzar los objetivos del pluralismo, pues lejos de propiciar la diversificación de las relaciones sociales lo que consiguen es su control y verificación.

Además, es muy importante que sean voluntaras por otra razón. En algunas sociedades existen ciertas organizaciones sociales que forman parte de sus costumbres y tradiciones. Se entra a ellas más por inercia que por la libre determinación. En estos casos no existe coacción expresa para adherirse a ellas, sin embargo, no contribuyen al logro de los objetivos del pluralismo debido a que tampoco propician la diversificación de las relaciones sociales y, en lugar de abrir canales de comunicación e interacción entre diversos sectores sociales, lo que producen es la cristalización y estancamiento de los vínculos colectivos preexistentes. ${ }^{17}$

Por lo que se refiere a la afiliación múltiple, su existencia resulta importante porque es lo que permite que un mismo individuo pueda pertenecer simultáneamente a varios tipos de organizaciones, lo cual constituye una palanca mucho más poderosa que la afiliación voluntaria para diversificar las relaciones sociales. Las organizaciones excluyentes y cerradas no sólo contribuyen poco al logro de los objetivos pluralistas, sino que además encierran en sí mismas un conflicto

${ }^{17}$ Véase Jean Blondel, Introducción al estudio comparativo de los gobiernos, 1972, Madrid, Revista de Occidente. 
potencial de alcances explosivos, capaces de producir la desintegración y descomposición social. ${ }^{18}$

Estas dos condiciones que deben satisfacer las organizaciones sociales son las que permiten que se desempeñen sus funciones básicas, sin las cuales es imposible alcanzar los objetivos generales del pluralismo social. Son muchos los autores que se han referido a la variedad e importancia de estas funciones básicas, y de entre todas ellas conviene destacar a las que podrían considerarse más importantes:

1. Operar como fuente de nuevas opiniones, independientes de las del Estado.

2. Realizar la difusión de estas opiniones e ideas.

3. Adiestrar a los individuos en las diversas habilidades políticas.

4. Alentar e introducir a éstos en las actividades políticas.

5. Brindar una identidad particular y específica a sus miembros. ${ }^{19}$

Como se deduce de estas funciones específicas, muchas organizaciones pueden ubicarse simultáneamente tanto en el pluralismo político como en el pluralismo social. Así, a pesar de que muchas organizaciones sociales no tienen objetivos políticos explícitos, en la realidad actúan también dentro de este ámbito, particularmente operando como freno y contención del poder del Estado. De este modo, muchos teóricos del pluralismo conciben que tanto el pluralismo político como el social tienen como función primordial la de atenuar la fuerza de la autoridad política. Sin embargo, es necesario señalar que en este sentido la mayor parte de las organizaciones sociales cumplen un doble propósito. Uno de ellos es el ya señalado, pero el otro contrasta con el primero, ya que consiste en contribuir al establecimiento y reproducción de los esquemas de autoridad social y política que requiere toda sociedad.

${ }^{18}$ Véase William Kornhauser, Aspectos políticos de la sociedad de masas, 1969, Buenos Aires, Amorrortu.

${ }^{19}$ Una clasificación similar a ésta la ofrecen Seymur Martin Lipset, Martin A. Trow y James Coleman, Union Democracy. The internal politics of the International Typographical Union, 1977, New York, The Free Press. 
ROBERTO GARCÍA JURADO

Cuando se habla del pluralismo es muy común referirse al primer cometido pero no al segundo, más aún, un señalamiento de este tipo cae fuera del espíritu original de los pluralistas. Sin embargo, resulta inevitable percatarse de esta doble función. Las organizaciones sociales contribuyen al ejercicio y reproducción de la autoridad política debido a que para su operación ellas mismas requieren principios, estructuras y procedimientos de orden y organización, es decir, requieren de estructuras jerárquicas en donde la relación de mando-obediencia se dé regularmente. Aunque muchas estructuras básicas de la sociedad como la familia, la escuela, la iglesia, el ejército, la empresa o las actividades deportivas cumplen una buena parte de esta función reproductora de los esquemas de autoridad, las organizaciones sociales contribuyen de manera decisiva en esa tarea, ya que mientras las primeras tienen en la mayor parte de los casos un carácter obligatorio, ineludible e impuesto, las segundas son generalmente voluntarias. Esta diferencia es relevante porque en tanto en el primer caso la imposición de la autoridad puede generar malestar y rechazo, en el segundo, cuando el individuo elige voluntariamente adherirse a ellas, la autoridad se convierte en ingrediente útil y necesario para alcanzar los propósitos del individuo. ${ }^{20}$

Existe además otro medio por el cual las organizaciones sociales contribuyen al ejercicio y la reproducción de la autoridad. Éste consiste en proporcionar a los individuos una red de asociaciones y entidades sociales muy amplia y variada, por medio de las cuales los individuos pueden identificarse de manera muy cercana a un grupo social, llenándose así en alguna medida la enorme brecha que separa al individuo del conjunto de la sociedad, al ciudadano del Estado. La asociación de los individuos a este tipo de organizaciones atenúa en cierto modo el sentimiento de impotencia, anonimato e incapacidad que frecuentemente experimentan los hombres. Cuando los individuos se ligan a

${ }^{20}$ Véase Harry Eckstein, “A theory of stable democracy”, en Division and cohesion in democracy. A study of Norway, 1996, New Jersey, Princeton University Press; y Carole Pateman, op. cit. 
este tipo de organizaciones, es más probable que compartan el interés de la sociedad en conservar el orden social y, por lo tanto, las instituciones de autoridad política, manteniéndose al margen o distantes de aventuras políticas extremas o de acciones tendientes a minar las estructuras de la autoridad social. ${ }^{21}$

No obstante, además de las coincidencias y similitudes entre el pluralismo político y el social, debe notarse que el segundo es susceptible de las mismas críticas hechas al primero. Ambos atribuyen al conjunto de los ciudadanos más o menos la misma capacidad de organización, la misma posibilidad de ejercer presión sobre el Estado y la misma probabilidad de obtener los éxitos que persiguen. En los dos casos se repara poco en que cada grupo social tiene distintas capacidades asociativas, esto es, que los de mayores recursos económicos tienen más que los de menores, que los mejor educados tienen más que los peor educados, que los productores tienen más que los consumidores, y que los empresarios tienen más que los trabajadores. Consecuentemente, también se atribuye la misma posibilidad de presión a todos los grupos sociales, sin reparar en que cada uno posee una distinta, lo que a menudo conduce a atribuirle al pluralismo mayores virtudes de las que tiene. ${ }^{22}$

Por último, no puede concluirse este punto sin advertir una notable paradoja. Como se mencionó antes, el objetivo más importante del pluralismo social es fomentar la integración y cohesión social mediante los vínculos y contactos de las organizaciones sociales que supone. El efecto principal que se consigue con ello es debilitar o borrar las principales líneas de división social que impliquen la posibilidad de conducir al conflicto y la secesión. Sin embargo, una de las limitaciones más importantes del pluralismo es que ahí donde es más necesario es precisamente donde es menos posible. Esto se debe a que en las sociedades heterogéneas, plurales y en proceso de integración, en donde

${ }^{21}$ Véase Seymur Martin Lipset y Earl Raab, La política de la sinrazón. El extremismo de derecha en los Estados Unidos, 1790-1977, 1981, México, FCE.

${ }^{22}$ Véase Wright Mills, La élite del poder, 1993, México, FCE. 
ROBERTO GARCÍA JURADO

las líneas básicas de la división social están más marcadas y, por lo tanto, más necesarios son los vínculos de comunicación, es precisamente donde más reticencia hay para que los miembros de una organización social específica acepten en ella a individuos de un grupo social distinto. La adhesión voluntaria y múltiple de los individuos a las organizaciones que pone como condición el pluralismo social se dificulta enormemente; se encuentra con el nada despreciable obstáculo de que en una sociedad de tales características los individuos sólo tienen disposición para integrarse a las organizaciones de su propia comunidad, despreciando e incluso rechazando a las otras. Así pues, resulta paradójico descubrir que donde más necesaria es la presencia del pluralismo social es donde menos factibilidad hay para su operación. Sin embargo, a pesar de estos obstáculos, puede considerarse que este tipo de pluralismo es uno de los recursos disponibles para combatir el conflicto y la desintegración social, y aunque su aplicación sea difícil, eso no quita que pueda contribuir en alguna medida.

\section{El pluralismo cultural}

Tradicionalmente, el pluralismo cultural ha recibido mucho menos atención que el político y el social, más aún, podría decirse que la teoría clásica del pluralismo se refería únicamente a estos dos tipos de pluralismo. No obstante, es probable que en la actualidad el sentido más fuerte e importante del pluralismo sea precisamente el cultural, pero a pesar de su indiscutible relevancia, es muy común que el pluralismo cultural reciba muchas más objeciones para ser aceptado como modelo prescriptivo que los otros dos tipos.

La teoría clásica y contemporánea de la democracia ha partido siempre de la premisa de que los gobiernos democráticos se asientan y adaptan mejor a una sociedad culturalmente homogénea. Esto quiere decir que siempre se le han otorgado más probabilidades de estabilidad política a las democracias de este tipo, esto es, que en caso de que fuera posible elegir el tipo de sociedad sobre la cual construir la demo- 
cracia, debe preferirse siempre la homogeneidad a la heterogeneidad cultural.

Sin embargo, la configuración de la comunidad política nunca ha sido determinada por los factores culturales, antes que ellos, han prevalecido siempre consideraciones de otro tipo, ya sean guerras, conquistas y herencias políticas o, incluso, el simple azar y accidente histórico. Así, muy pocos Estados modernos pueden considerarse culturalmente homogéneos, y aun éstos, debido a los incesantes flujos migratorios y a la realineación de las fronteras geopolíticas, son susceptibles de sufrir alteraciones en su composición.

A pesar de esta fatalidad histórica, el precepto se mantiene; así sea al nivel de un ideal, la teoría de la democracia sostiene que es mejor disponer de una sociedad culturalmente homogénea.

No obstante, de manera paralela, al menos desde el siglo XVII, la sociedad occidental se ha visto obligada a desarrollar un espíritu de tolerancia y aceptación del otro, de aquel que aun proviniendo de su misma civilización es distinto, e incluso de aquel otro que proviene de una cultura diferente, con quien hace falta mucha más tolerancia. De este modo, aunque la tolerancia se aplicó inicialmente de manera principal a las diferencias religiosas, poco a poco se ha ido extendiendo a otros rasgos culturales, como la lengua, las costumbres y las tradiciones. Así, la tolerancia que en un principio fue una necesidad imperiosa para la conservación de la sociedad europea, se ha convertido al paso del tiempo en un valor y un precepto moral indiscutible, sobre todo cuando se le traduce a los términos del pluralismo cultural, en donde se alude a grupos humanos más definidos. ${ }^{23}$

Como puede verse, aunque en términos discursivos la democracia y el pluralismo cultural parecen formar parte de un solo ideal, en realidad llevan implícito un principio de conflicto; la primera pondera positivamente los valores de la convivencia política en la homogeneidad y el segundo los de la heterogeneidad.

${ }^{23}$ Véase Michel Walzer, On toleration, 1997, New Haven and London, Yale University Press. 
ROBERTO GARCÍA JURADO

Sin embargo, como se dijo antes, muy pocos Estados modernos son culturalmente homogéneos, por los que las democracias occidentales se han visto obligadas a hacer de la necesidad virtud, convirtiendo al pluralismo cultural en un precepto positivo. Así, como puede verse, aunque por otros medios, el pluralismo cultural también ha adquirido una valoración positiva. Tal vez no haya alcanzado el grado prescriptivo del pluralismo político y social, pero al igual que éstos, la mayor parte de los sistemas democráticos presumen tenerlo incorporado a sus principios ideológicos constitutivos.

No obstante que al paso del tiempo los tres tipos de pluralismo han obtenido una valoración medianamente similar, es necesario advertir que se trata de pluralismos distintos. La distinción entre el pluralismo político, social y cultural podría parecer una simple diferenciación de los campos y los sectores de la sociedad a los que se aplica el concepto, sin embargo, se trata de tres tipos distintos. El pluralismo político es esencialmente un pluralismo de competencia, una contienda entre diversas fuerzas políticas que compiten sobre un mismo terreno para obtener o presionar al poder político. El pluralismo cultural es distinto, es sobre todo un pluralismo de identidades, una constelación de diferentes grupos humanos que se encuentran unidos por ciertos aspectos pero que pretende conservar para cada uno de ellos un cierto grado de identidad y diferencia con respecto a los otros, ya se trate de cuestiones como la raza, la lengua o la religión. Por último, el pluralismo social puede verse como un híbrido, como una mezcla de los principios de los otros dos tipos. En el pluralismo social existen tanto la competencia como la identidad. Este pluralismo describe cómo muchos grupos sociales compiten entre sí para obtener los intereses que persiguen, pero al mismo tiempo brindan a sus miembros un espíritu de identidad microsocial. $^{24}$

Como puede verse, cada uno de estos tipos de pluralismo es diferente, pero el pluralismo cultural se diferencia adicionalmente del político

\footnotetext{
${ }^{24}$ Véase Werner Becker, La libertad que queremos, 1990, México, FCE; y Jean Blondel, op. cit.
} 
y social en un aspecto esencial. Esa diferencia es que mientras más heterogénea es una sociedad, más importancia adquiere el pluralismo cultural, y a la inversa, en tanto más homogénea es una sociedad, el pluralismo cultural es menos necesario.

El pluralismo cultural implica la existencia de una sociedad heterogénea, de una sociedad plural y, en ciertos casos, incluso de una sociedad fragmentada. En este sentido, el pluralismo cultural podría ser entendido como el eufemismo para designar a una sociedad multiétnica. Sin embargo, también puede ser considerado como un concepto para describir un cierto avance en la resolución del conflicto étnico implícito, esto es, cuando una sociedad culturalmente heterogénea tiene problemas serios de integración y convivencia se le aplican conceptos como el de Estado multinacional o sociedad multiétnica, pero cuando estos conflictos son tenues o controlables, entonces se habla de pluralismo cultural. Sin embargo, a pesar de que el pluralismo cultural describe de manera positiva la relación y convivencia de distintos grupos dentro de una misma sociedad, no debe suponerse que eso signifique la resolución definitiva de los problemas y las diferencias. Más aún, los cambios sociales que se están produciendo en el mundo contemporáneo no parecen tender a la supresión del conflicto, sino que dan más fuerza y aliento a la diversidad de grupos culturales existentes y aun a aquellos que parecían extintos.

A partir de estos cambios, el pluralismo cultural ha recibido toda una elaboración y expresión teórica en la corriente que se ha denominado multiculturalismo, la cual se ha presentado como un serio desafío a la tradición y el pensamiento liberal.

El multiculturalismo se ha desarrollado sobre todo en las últimas dos décadas del siglo Xx. Su objetivo es plantear alternativas para resolver los problemas de justicia social y política de las sociedades multiétnicas, tanto de las que históricamente han tenido ese carácter, como las de reciente creación; aquellas que debido a los crecientes flujos migratorios han visto diversificarse a su población al grado de dar origen a una sociedad nueva. En muchas de estas sociedades los esquemas jurídicos de igualdad de derechos y aplicación universal de 
ROBERTO GARCÍA JURADO

la ley no pueden considerarse los únicos recursos de la justicia política y social, más aún, tal vez su aplicación indiscriminada produzca injusticia, ya que las distintas condiciones especificas de cada grupo social se verán afectadas de manera desigual por un criterio legal general e indiferente. La igualdad ante la ley y la universalidad de ésta tienen la virtud de otorgar una igualdad de oportunidades a los individuos de una sociedad homogénea, pero en los casos donde no es así, en donde existen minorías culturales, la dinámica social natural produce una competencia inequitativa, dando mayores y mejores oportunidades a aquellos que pertenecen al grupo cultural mayoritario. ${ }^{25}$

El multiculturalismo propone que para corregir esta desigualdad es necesario que el estado y la ley reconozcan esta diferencia y otorguen derechos diferenciados a estos grupos con el fin de favorecerles clara y abiertamente, protegiendo así su identidad y existencia. Sin embargo, la desigualdad ante la ley y el reconocimiento de diferentes categorías de ciudadanos contraviene los principios del Estado liberal. Para los liberales, el pluralismo es sólo un medio para reconocer la diferencia cultural ya existente, respetando a los grupos ya establecidos, pero no debe ser nunca un medio para producir deliberadamente la diversidad. El pluralismo debe tratar de acercar y fundir a los diferentes grupos culturales en una convivencia cívica respetuosa, por lo que acusan al multiculturalismo de atentar contra este propósito, de fomentar el encono y la desunión. Así, como puede verse, los principios de la justicia liberal y la justicia multicultural albergan un conflicto de difícil resolución. ${ }^{26}$

\footnotetext{
${ }^{25}$ Las tesis más conocidas de esta corriente pueden encontrarse en Charles Taylor, El multiculturalismo y la política del reconocimiento, 1993, México, FCE; Michel Sandel, El liberalismo y los límites de la justicia, 2000, Barcelona, Gedisa; y Will Kymlicka, Ciudadanía multicultural, 1996, Barcelona, Paidós.

${ }^{26}$ Véase Giovanni Sartori, La sociedad multiétnica. Pluralismo, multiculturalismo y extranjeros, 2001, España, Taurus; y Samuel Huntington, El choque de civilizaciones, 1998, México, Paidós.
} 
Este conflicto teórico tiene una inmediata traducción en el debate de la política actual, ya que muchas sociedades enfrentan serios problemas de integración y convivencia cultural, por lo que los partidarios de uno y otro bando tratan de dirigir las políticas públicas de acuerdo a su concepción teórica, lo cual genera fuertes tensiones en el terreno legislativo y gubernamental.

Como se ha mostrado, el pluralismo tiene tres modalidades que, aunque comparten muchos rasgos comunes, es conveniente distinguir y diferenciar. No obstante, a lo largo de este trabajo se ha presentado como un rasgo positivo y que alcanza el valor de la prescripción en las democracias occidentales. Sin embargo, es necesario destacar su valoración positiva no debe traducirse siempre en prescripción, al menos no en todos los casos. Es decir, si bien la democracia pluralista es el modelo que se ha implantado en países como Estados Unidos con cierto éxito, esto no implica que dicho modelo deba implantarse en otro tipo de sociedades.

Presentar al pluralismo como el único modelo de relación entre los diferentes grupos sociales y el gobierno puede tener serias implicaciones. Encontrándonos en un momento del devenir mundial en el cual muchos países están transitando a la democracia, resulta bastante delicado y comprometer inducirlos a que en su transformación adopten las instituciones y prácticas de la democracia pluralista. Es necesario advertir que si en ciertas sociedades este modelo de relación ha resultado apropiado, en otras puede resultar inadecuado. Se requiere entonces que se muestren las diferentes alternativas de organización y los distintos tipos de institucionalización de la democracia, lo cual ofrecerá muchas más ventajas y probabilidades que la panorámica unimodal. 
